\title{
Finding Environmental Knowledge in SCUBA-Based Textual Materials
}

\author{
Cemal Gündoğdu${ }^{1}$, Yalın Aygün ${ }^{1}$, Mehmet Ilkım \\ ${ }^{1}$ Faculty of Sport Sciences, Inonu University, Malatya, Turkey \\ Correspondence: Yalın Aygün, Faculty of Sport Sciences, Inonu University, 44280, Malatya, Turkey.
}

Received: December 2, 2017

Accepted: January 9, 2018

Online Published: January 20, 2018

doi:10.11114/jets.v6i2.2838

URL: https://doi.org/10.11114/jets.v6i2.2838

\begin{abstract}
As marine environments within the adventure domain are future key-settings for recreational SCUBA diving experience, SCUBA-based textual materials should provide insight into environmental knowledge that is well connected to the novice divers' behaviour and attitude. This research is concerned with a major recreational SCUBA diver manual for novice divers from a position that seeks to explore its focus and scope of environmental knowledge in semantic networks. However, results obtained from thematic analyses of environmental knowledge emerged two sub-themes: marine-based conservation and aquatic life. Analyses of textual data indicated that the manual has groundling statements and notes on environmental knowledge. Furthermore, analyzing manual' environmental documents showed that there is no skill-related knowledge, which attributes to SCUBA divers' environmental behaviour and attitude towards underwater environment.
\end{abstract}

Keywords: recreation, leisure-adventure, marine tourism, water-based activities, diving

\section{Introduction}

This article first introduces the theoretical background of the research and its context. Then it presents the methodological stage of the qualitative approach. The study gives a perspective of textual data and then draws conclusions based on the strength of qualitative data set to gain insight into research problem.

Water-based leisure adventure activities host a range of tourism and recreational pursuit undertaken in or in relation to water resources including lakes, dams, canals, creeks, streams, rivers, waterways, marine costal zones, seas, oceans and ice-associated areas (Jennings, 2007). When human beings descent beneath the surface of the water, they are exposed to various physical effects due to water density, however. The main physical features of underwater environment consist of ambient pressure that may vary approximately every few meters, high heat transmission, low visibility, distortion of visual and auditory signals, waves, tides and currents (Shilling, Werts, \& Schandelmeier, 1976). Recreational participation of human with underwater environment has strong links to SCUBA diving. Recreational SCUBA diving has became one of the fastest growing leisure-adventure activity in popularity over the years, attracting millions of participants around the world (Miller, 1993; Orams, 1999). SCUBA is the acronym for Self-Contained Underwater Breathing Apparatus. Aqualung, first safe reliable prototype SCUBA unit for underwater diving, was explored by Jacques Couteau and Emily Gagnan in 1943, allowing humans to travel under the water to explore and experience the aquatic environment (Kindwall, 2002). Today, SCUBA is defined as a vehicle to a wide range of activities and interrelated skills that create adventure, fun and recreation no matter how varied the participants' interests (Shreeves, 2010).

However, sustainability of recreational SCUBA diving is bound to the continued health of sensitive environmental recourses of underwater such as natural formations, aquatic objects and living creatures (Anderson \& Loomis, 2011). Research into recreational SCUBA diving addressing divers' behaviour, attitude and knowledge is necessary, therefore. There are various researches on SCUBA divers' specialization. For example, Anderson \& Loomis, (2011) noted that specialized divers felt a stronger obligation not to touch corals and to pick up garbage from the sea floor than did less specialized divers. Findings of Thapa, Graaefe, \& Meyer, (2005)' research showed that specialization in SCUBA diving is related to knowledge, as divers who had higher levels of specialization tended to have stronger marine-based environmental knowledge. Barker \& Roberts, (2004) found that pre-dive briefings alone are insufficient to reduce diver damage to the underwater environment. Musa, Seng, Thirumoorthi, \& Abessi, (2010) reported that SCUBA diving experience, parameters of duration of involvement, number of dives, self-rating experience and diving frequency influence underwater behaviour. All of these authors recognize that the divers' role in marine environmental conservation is crucial as their engagement with this activity can end up with detrimental impact to the fragile ecology. 
To date, however, not any existing research has addressed how recreational SCUBA divers' behaviour and attitude towards marine-based conservation can be affected by knowledge in the textual materials of SCUBA. This is the unique contribution of the present research.

Learning to dive gives recreational divers an opportunity to become more familiar with the aquatic environment, and also it can contribute to improve awareness towards marine-based conservation (Graver, 2010).

As marine environments within the adventure domain are future key-settings in recreational SCUBA diving experience, SCUBA-based textual materials should provide insight into environmental knowledge that is well connected to the novice divers' behaviour and attitude. In the present research, we posed developmental puzzle driven by this overarching research question (Mason, 2002): what we can grasp from the textual materials focusing on the environmental knowledge, and how we can connect this with the novice SCUBA divers' environmental behaviour and attitudes in a proper manner?

The strength of the article is indeed rising awareness and stimulating learning for a sector in which on the one hand only general advice is provided and which, on the other hand, is very important for marine nature conservation. The purpose of this study therefore, was to examine a major recreational SCUBA diver manual for novice divers from a position that seeks to understand the focus and scope of its environmental knowledge in semantic network.

\section{Method}

The present research captures environmental aspects of the recreational SCUBA diver manual penned by Turkish Underwater Sports Federation (TSSF, 2017). This research is a theoretical investigation and we adopted qualitative research methods. Qualitative document analysis was also applied through the recreational SCUBA diver manual considering marine-based conservation and aquatic life within the predetermined context of environmental knowledge (Creswell, 2007). These contexts were also established as criteria for document analysis conducted throughout the entire manual (Patton, 2002). How deeply we analyze the manual depends on the central question: what we can grasp from the textual materials focusing on the environmental knowledge, and how we can connect this with the novice SCUBA divers' environmental behaviour and attitudes in a proper manner? The manual is 79 pages, and it includes twelve chapters, couple with one appendix. The titles of each chapter is administrative lesson, basic equipments, diving signals, pressure and volume relationship, SCUBA equipment, physics and physiology, buoyancy control device, diving suits and auxiliary equipments, care and storage of equipments, rescue yourself and others, safe diving rules and diving spot selection and conservation. Appendix of the manual has systematic knowledge about decompression tables, however. This manual is given recreational divers, who dive for pleasure, leisure and social experience as well as to be granted a certificate after completion of a diving course (Nevo \& Breitstein, 1999). Document analysis was applied through software package NVivo 11 Plus to search for specific statements, themes and all possible meanings towards social phenomenon.

\section{Results}

\subsection{Marine-Based Conservation}

Recreational divers have a key-role in water-based marine conservation as their activities can end up with detrimental impact to the fragile ecology. Diving industries are also responsible for developing divers' pearls of wisdom providing body of environmental knowledge in their textual materials. Upon scanning the textual material, we found that scope of the recreational diver manual in the sense of marine-based conservation is skimp. For example, any amenable knowledge regarding underwater skill levels that strongly link to divers' environmental behaviour and attitude was not found in the manual. However, the introduction chapter of this manual draws attention to marine conservation awareness through short descriptions, two expressions are:

"Dear underwater-lover and nature-friendly candidate; welcome to our recreational SCUBA diver course"

"In this training, you will be guided how to protect your cultural and natural assets that are under our seas as respectful divers".

The quotes demonstrated that the introduction chapter of the manual emphasized on the inventive and stimulus rundowns rather than detail descriptions in order to create collective marine-based conservation awareness. In addition, the manual has a two-paged chapter, named with diving spot selection and conservation, for example:

"The sea is not an endless source and any amenable precaution should be taken to avoid harm to it".

"It is not necessary to touch an object or creature underwater".

3.2 Aquatic Life

There is no doubt that the growth in recreational SCUBA diving has been mostly facilitated by wide range of aquatic 
creatures and formations. This certainly assist enhance people's interest in this activity. The explanations that consist of aquatic life awareness in the recreational SCUBA diver manual were found scanty. For example, there is no statement in the manual towards emergency first response that creates confidence to care aquatic creatures. Moreover, we did not come cross any manual chapter or a statement relevant to fish identification that create pre-awareness among novice divers.

\section{Discussion}

This research is concerned with a major recreational SCUBA diver manual for novice divers from a position that seeks to understand its focus and scope of environmental knowledge in semantic network.

In an effort to gain insight into the manual in the perspective of environmental knowledge, we captured that each textual material has groundling statements and notes. Moreover, we deduced that there is no skill-related knowledge which attributes to SCUBA divers' environmental behaviour and attitude towards underwater environment. However existing research into divers' marine-based environmental knowledge, behaviour and attitude pointed out that each of these contexts are interrelated in terms of sustainability of recreational SCUBA diving. Coral reefs are very fragile, and physical contact usually brings about death of the corals. Damage to corals by recreational SCUBA divers is generally through intentional or accidental physical contact with their hands, body, equipment and fins (Talge, 1992). SCUBA divers who have poor buoyancy control skills can enormously damage the aquatic environment. Likewise, poor fining techniques stir up silt and sand on the bottom of ocean that suffocate and kill aquatic organisms (Fishman, 1991). Experience SCUBA divers who have better control over their buoyancy establishment and fining technique can minimize their impact on coral reefs. In other words, there is a negative association between the dive experience and the level of damage on corals (Anderson \& Loomis, 2011; Musa, Seng, Thirumoorthi, \& Abessi, 2010; Roupheal \& Inglish, 1997; Thapa, Graefe, \& Meyer, 2005).

As a result, SCUBA diver manual prepared for novice divers should include more comprehensive environmental knowledge as the divers' environmental behaviour and attitude generally shaped through this way. Similarly, introduction chapter of the manual should be further enriched including more specific examples such as conserving coral reefs and organism or indigenous aquatic creatures.

It could be also very interesting to develop further the research in a next article and analyse possible development of SCUBA manuals, in order to provide divers with knowledge about possible impacts of their behavior underwater, and dynamies of marine ecosystems. In this way they could be stimulated to feel part of it and consider ecosystems not only places to visit fir leisure but environments where they belong to.

Possible alternative structure of manuals could be examined by participatory approaches, in order to propose possible developments. Divers could be stimulated ro reading and practical experiencing at the same time not only for a light-approach of leisure activity, but for a more involving knowledge-based adventure.

\section{Acknowledgements}

An earlier version of this paper was orally presented at the 22nd annual Congress of the European College of Sport Science, Germany, Essen, on July 5 - 8, 2017. We would like to thank all participants who contributed to this work through their comments on an earlier draft.

\section{Declaration of Conflicting Interests}

The author(s) declared no potential conflicts of interest with respect to the research, authorship, and/or publication of this article.

\section{References}

Anderson, L. E., \& Loomis, D. K. (2011). Scuba diver specialization and behavior norms at coral reefs. Coastal Management, 39(5), 478-491. https://doi.org/10.1080/08920753.2011.598813

Barker, N. H. L., \& Roberts, C. M. (2004). Scuba diver behaviour and the management of diving impacts on coral reefs. Biological Conservation, 120, 481-489. https://doi.org/10.1016/j.biocon.2004.03.021

Creswell, J. W. (2007). Qualitative inquiry \& research design: choosing among five approaches (2. Bask1). United States of America: Sage Publication Ltd.

Fishman, D. J. (1991). Loving the reef to death. Sea Frontiers, 37(2), 14-22.

Graver, D. K. (2010). Scuba Diving (4th editio). USA: United Graphics.

Jennings, G. (2007). Water-based tourism, sport, leisure, and recreation experience. In G. Jennings (Ed.), Water-based tourism, sport, leisure, and recreation experience (1th editio, pp. 1-16). United States of America: Elsevier. https://doi.org/10.1016/B978-0-7506-6181-2.50005-1 
Kindwall, E. P. (2002). A short history of diving and diving medicine. (A. A. Bove \& J. C. Davis, Eds.). Philadelphia: PA: W. B. Saunders.

Mason, J. (2002). Qualitative researching (2th Editio). Great Britain: Cromwell Press.

Miller, M. L. (1993). The rise of coastal and marine tourism. Ocean and Coastal Management, 20(3), 181-199. https://doi.org/10.1016/0964-5691(93)90066-8

Musa, G., Seng, W. T., Thirumoorthi, T., \& Abessi, M. (2010). The influence of scuba divers' personality, experience, and demographic profile on their underwater behavior. Tourism in Marine Environment, 7(1), 1-14. https://doi.org/10.3727/154427310X12826772784757

Nevo, B., \& Breitstein, S. (1999). Psychological and behavioral aspect of diving. Flagstaff, AZ: Best Publishing Co.

Orams, M. (1999). Marine Tourism: Developments, impacts and management. New York: Routledge. https://doi.org/10.4324/9780203197110

Patton, M. Q. (2002). Qualitative research \& evaluation methods. Qualitative Inquiry (1th editio). United States of America: Sage Publication Ltd.

Roupheal, T., \& Inglish, G. (1997). Impacts of recreational scuba diving at sites with different reef topographies. Biological Conservation, 82, 329-336. https://doi.org/10.1016/S0006-3207(97)00047-5

Shilling, C. W., Werts, M. F., \& Schandelmeier, N. R. (1976). The underwater handbook: A guide to physiology and performance for the engineer. New York: Plenum Press.

Shreeves, K. (2010). Adventures in diving. Canada: PADI.

Talge, H. (1992). Impact of recreational divers on scleratinian corals at Looe Key, Florida (Vol. 2, pp. 1077-1082).

Thapa, B., Graaefe, A. R., \& Meyer, L. A. (2005). Moderator and mediator effects of scuba diving specialization on marine-based environmental knowledge-behavior contingency. The Journal of Enviromental Education, 37(1), 5367. https://doi.org/10.3200/JOEE.37.1.53-68

Thapa, B., Graefe, A. R., \& Meyer, L. A. (2005). Moderator and mediator effects of scuba diving specialization on marine-based environmental knowledge-behavior contingency. The Journal of Environmental Education, 37(1), 53-67. https://doi.org/10.3200/JOEE.37.1.53-68

TSSF. (2017). One star diving manual (11th editi). Istanbul: CNS Agency.

\section{Copyrights}

Copyright for this article is retained by the author(s), with first publication rights granted to the journal.

This is an open-access article distributed under the terms and conditions of the Creative Commons Attribution license which permits unrestricted use, distribution, and reproduction in any medium, provided the original work is properly cited. 